Dhaka Univ. J. Biol. Sci. 23(1): 53-60, 2014 (January)

\title{
IN VITRO CONTROL OF FUSARIUM SOLANI AND F. OXYSPORUM THE CAUSATIVE AGENT OF BRINJAL WILT
}

\author{
M. A. Bashar AND Mina ChaKma \\ Department of Botany, University of Dhaka, Dhaka-1000, Bangladesh
}

Key words: Antagonist, Trichoderma, Aspergillus, Penicillium, Brinjal, Fungicides

\begin{abstract}
Seven soil fungi viz. Aspergillus flavus, A. fumigatus, A. niger, A. terreus, Penicillium sp., Trichoderma harzianum and $T$. viride associated with the rhizosphere, non-rhizosphere and rhizoplane of brinjal plants were selected to observe their antagonistic potential against the test fungi Fusarium oxysporum and F. solani. Out of seven soil fungi T. harzianum was found most effective to control the growth of both the test fungi. Plant parts extract of Allium sativum, Asparagus racemosus, Azadirachta indica, Cassia alata, Ocimum sanctum, Zingiber officinale and Datura metel were evaluated for their in vitro efficacy at 5, 10 and $20 \%$ concentration against the test fungi. Datura metel, and C. alata and A. indica was found most efficient inhibitor of $F$. solani and F. oxysporum, respectively. Five fungicides viz., agridazim $50 \mathrm{wp}$, cozeb $80 \mathrm{wp}$, newban $50 \mathrm{wp}$, sunvit $50 \mathrm{wp}$ and vitavax $200 \mathrm{~B}$ were evaluated for their in vitro efficacy at $500 \mathrm{ppm}$ concentration against F. solani and F. oxysporum. Vitavax 200B was found most efficient inhibitor of both the test fungi.
\end{abstract}

\section{Introduction}

Brinjal (Solanum melongena L.) is the most popular vegetables in Bangladesh and grows in an area of about 29,132 ha producing about $1,87,705$ in tons ${ }^{(1)}$. Among the diseases that attack brinjal, wilt is one of them caused by Fusarium oxysporum f. sp. melongenae and F. solani(2). Among the destructive diseases of brinjal, wilt has significant impact on the yield of the crop.

Now-a-days, many inorganic fungicides are used frequently to control plant diseases. Therefore, it is necessary to evaluate the efficacy of the fungicides against the targeted pathogens of brinjal. Various workers in different countries of the world evaluated the effficacy of various fungicides against different brinjal pathogens ${ }^{(3-5)}$.

In the recent years scientists have begun to understand the consequences of the widespread and repeated use of chemical fungicides that threaten human interest. Fungi are potentially better biocontrol agents suggesting one of the alternatives. Presently, different species of Trichoderma are used successfully to control different plant pathogens ${ }^{(6-10)}$. Plant parts and their constituents of some higher plants have already been reported to be of successful nature of fungitoxicants because of their lesser phytotoxicity, systemicity, easily biodegradability and favourable effects for the growth of the host ${ }^{(11-14)}$. 
In Bangladesh, little information is available regarding the mycoflora of rhizosphere of brinjal and their role in biological control. Considering the above mentioned facts present investigation was undertaken with a view to in vitro controling of Fusarium solani and F. oxysporum, the natural enemies of brinjal.

\section{Materials and Methods}

A total of 21 soil fungi were isolated from the rhizosphere, non-rhizosphere and rhizoplane of healthy and wilted brinjal plants following tissue planting and serial dilution plate method from the selected cultivar during December 2011 to August 2012 directly from the field of BADC in Gazipur. Seven soil fungi viz., Aspergillus flavus, A. fumigatus, A. niger, A. terreus, Penicillium sp., Trichoderma harzianum and T. viride. were selected as the antagonists on the basis of their growth rate. Fusarium oxysporum and F. solani was selected as the test fungi. The antagonistic behavior of the selected antagonists against the test fungi was determined by colony interaction, volatile and non-volatile metabolites.

The antagonistic action of the selected fungi against the test fungi were performed by dual culture technique as described by Bashar and Rai(6). Assessment of colony interaction between the test fungi and soil fungi were done in terms of grades which were determined following the model of Skidmore and Dickinson ${ }^{(15)}$. The parameters used for the assessment of colony interaction were the width of inhibition zone, intermingled zone and per cent inhibition of radial growth ${ }^{(16)}$.

The effect of volatile and non-volatile substances of the soil fungi on the growth of the test fungi were performed following the methods described by Bashar and Rai(6).

Leaves of Azadirachta indicia A Juss., Ocimum sanctum L, Datura metel L,, Cassia alata L., roots of Asparagus racemosus L., bulbs of Allium sativum L. and tubers of Zingiber officinale Rosc were selected for screening of antifungal activity against the test fungi. The toxicity of the crude plant extract was determined against the test fungi following poisoned food technique ${ }^{(17)}$. The per cent inhibition of mycelial growth over control was calculated using the formula described by Bashar(3).

In vitro fungitoxicity of five fungicides viz., agridazim $50 \mathrm{wp}$, cozeb $80 \mathrm{wp}$, newban $72 \mathrm{wp}$, sunvit (copper oxychloride) and vitavax $200 \mathrm{~B}$ (carboxin, 37.5\%, thiram, 62.5\%) were tested against the test fungi at $500 \mathrm{ppm}$ concentration following poisoned food technique ${ }^{(17)}$.

\section{Results and Discussion}

The results of colony interactions between the test fungi and the soil fungi have been summarized in Table 1. Grade 3 was found to be the common type of colony interaction. From the results it is evident that out of seven soil fungi examined only Aspergillus niger, T. harzianum and T. viride exhibited strong antagonistic effects against the test fungi. 
All the tested soil fungi inhibited the radial growth of the test fungi in varied degrees in dual culture experiments on agar plates. In case of F. solani, T. harzianum showed highest inhibition of radial growth $(78.6 \%)$ followed by A. niger $(56.25 \%)$ and T. viride (50\%). Least inhibition of radial growth was noticed with Aspergillus terreus (23.53\%). The maximum inhibition of F. oxysporum was exhibited by T. harzianum $(70.59 \%)$ followed by A. niger $(65.21 \%)$, T. viride $(64.24 \%)$ and A. terreus (53.33\%). Least inhibition of radial growth was noticed with A. fumigatus (Table 1). High antagonistic activity of the Trichoderma spp. observed against the test fungi might be due to fast growing nature, rapid sporulation and toxic metabolite producing capacity. Similar observation was recorded by other workers against many plant pathogens ${ }^{(6-10)}$. Inhibition of growth of the test fungi by Aspergillus spp. is also in confirmatory with the similar reports of Upadhyay and Rai in case of other pathogenic fungi ${ }^{(18)}$.

Table 1. Colony interaction between soil fungi and test fungi.

\begin{tabular}{lccc}
\hline Soil fungi & Grade $^{*}$ & \multicolumn{2}{c}{ \% inhibition of radial growth } \\
\cline { 3 - 4 } & & Fusarium solani & F. oxysporum \\
\hline Aspergillus flavus & 3 & 43.33 & 57.14 \\
A. fumigatus & 3 & 34.78 & 34.78 \\
A. niger & 3 & 56.25 & 65.21 \\
A. terreus & 3 & 23.53 & 53.33 \\
Penicillium sp. & 3 & 37.50 & 52.00 \\
Trichoderma harzianum & 3 & 78.60 & 70.59 \\
T. viride & 3 & 50.00 & 64.24 \\
\hline
\end{tabular}

* = Grades from 1 (mutually intermingling growth) to 5 (mutual inhibition at a distance), based on Skidmore and Dickinson (1976). 3 = Intermingling growth where the fungus under observation has ceased growth and is being overgrown by another colony.

The growth inhibition of fungi on agar plates at a distance due to other fungi is commonly described due to the production of toxic metabolites by the antagonists which diffuse into the medium and cause growth inhibition. Competition for the nutrients, change in $\mathrm{pH}$, nutrient imbalance, mechanical obstruction and hyperparasitic behavior are involved in the colony interactions ${ }^{(15,16,18,19)}$.

Volatile substances emanating from the cultures of the soil fungi inhibited the radial growth of the test fungi to varied degrees. From the results it is evident that out of the seven soil fungi examined only T. harzianum, Penicillium sp. and A. niger exhibited better antagonistic effect against the test fungi (Table 2). In case of Fusarium solani, T. harzianum showed highest inhibition of radial growth (38.55\%) followed by Penicillium sp. (29.48\%) and A. niger (26.33\%) whereas T. harzianum showed $31.21 \%$ inhibition of radial growth of F. oxysporum which was followed by Penicillium sp. (27.06\%) and A. niger (20.15\%). In case of each test fungus $A$. fumigatus showed least inhibition of the test fungi (Table 2). 
The growth inhibition of the test fungi may be attributed to the presence of growth inhibitory substances in the metabolites ${ }^{(15)}$. The present observation suggests that there were qualitative and quantitative differences in the volatile substances produced by various soil fungi as they exhibited different degrees of growth inhibition of the test fungi. Some protective compounds recently isolated from endophytes are taxol, oocydin A, cryptocin, ambuic acid and jesterone ${ }^{(20,21)}$.

Table 2. Per cent inhibition of radial growth of the test fungi by volatile substances of soil fungi.

\begin{tabular}{lcc}
\hline \multirow{2}{*}{ Name of soil fungi } & \% inhibition of radial growth of the test fungi \\
\cline { 2 - 3 } & Fusarium solani & F. oxysporum \\
\hline Aspergillus flavus & 14.79 & 15.78 \\
A. fumigatus & 13.06 & 12.25 \\
A. niger & 26.33 & 20.15 \\
A. terreus & 15.75 & 19.00 \\
Penicillium sp. & 29.48 & 27.06 \\
Trichoderma harzianum & 38.55 & 31.21 \\
T. viride & 34.24 & 29.75 \\
\hline
\end{tabular}

* $=$ Test fungi.

All the antagonists showed varied degree of growth inhibition of the test fungi at different concentrations. Out of the seven antagonists, T. harzianum showed $87.17 \%$ inhibition of $F$. solani at $20 \%$ concentration which was followed by T. viride $(79.49 \%)$ and A. terreus $(76.92 \%)$. Similarly, the maximum inhibition of radial growth was observed with $T$. harzianum $(86.01 \%)$ against $F$. oxysporum which was followed by $A$. terreus $(83.33 \%)$ and T. viride $(82.05 \%)$ at the same concentration. The inhibition of the test fungi increased with the increase of concentration of culture filtrates in the culture medium (Table 3).

The inhibition of the radial growth of the test fungi due to non-volatile metabolites may be attributed to the production of antibiotic substances in the culture filtrates ${ }^{(22,23)}$, nutrient impoverishment ${ }^{(7,8)}$ and alteration of $\mathrm{pH}$ of the culture medium due to staling growth substances. Table 3 also shows that the per cent inhibition of the test fungi owing to soil fungi also differed. The differences might be due to differences in nature, quality and quantity of the inhibitory substances produced by the soil fungi(10,22-24).

Results of plant extracts on the radial growth of Fusarium solani and F. oxysporum are presented in Table 4. All the plant extracts showed varied degree of growth inhibition of the test fungi at different concentrations. Out of the seven plant extracts, Datura metel showed $66.67 \%$ inhibition of $F$. solani which was followed by A. racemosus $(65.71 \%)$ and A. indica $(57.14 \%)$. The highest inhibition of growth of $F$. oxysporum was observed with Cassia alata (74.68\%) which was followed by A.indica (62.03\%) and A. racemosus (56.96\%). 
The inhibition of the test fungi increased with the increase of the concentration of plant extracts in culture medium (Table 4).

Table 3. Effect of non-volatile substances of soil fungi on the radial growth of the test fungi at different concentrations.

\begin{tabular}{lcccccc}
\hline \multirow{2}{*}{ Name of soil fungi } & \multicolumn{3}{c}{ \% inhibition of radial growth at different concentrations } \\
\cline { 2 - 7 } & \multicolumn{3}{c}{ Fusarium solani* $^{*}$} & \multicolumn{3}{c}{ F. oxysporum $^{*}$} \\
\cline { 2 - 7 } & 5 & 10 & 20 & 5 & 10 & 20 \\
\hline Aspergillus flavus & 43.59 & 53.85 & 74.36 & 25.00 & 50.00 & 66.66 \\
A. fumigatus & 33.33 & 56.41 & 71.36 & 25.00 & 69.44 & 80.56 \\
A. niger & 48.71 & 64.10 & 74.36 & 16.57 & 27.78 & 72.22 \\
A. terreus & 48.72 & 53.85 & 76.92 & 27.77 & 38.89 & 83.33 \\
Penicillium sp. & 38.46 & 58.97 & 69.23 & 58.33 & 72.22 & 80.56 \\
Trichoderma harzianum & 76.92 & 82.05 & 87.17 & 75.00 & 82.05 & 86.01 \\
T. viride & 51.28 & 56.41 & 79.49 & 72.22 & 77.78 & 82.05 \\
\hline
\end{tabular}

* $=$ Test fungi

Table 4. Effect of plant extracts on the radial growth of the test fungi at different concentrations.

\begin{tabular}{lcccccc}
\hline \multirow{2}{*}{ Name of plant } & \multicolumn{4}{c}{ \% inhibition of radial growth at different concentrations } \\
\cline { 2 - 7 } & 5 & 10 & 20 & 5 & 10 & 20 \\
\cline { 2 - 6 } & 19.87 & 27.56 & 53.85 & 17.63 & 25.0 & 34.21 \\
\hline Allium sativum & 40.00 & 42.86 & 65.71 & 44.30 & 46.83 & 56.96 \\
Asparagus racemosus & 21.43 & 34.30 & 57.14 & 24.05 & 41.77 & 62.03 \\
Azadirachta indica & 36.10 & 44.40 & 50.00 & 46.83 & 49.36 & 74.68 \\
Cassia alata & 16.67 & 22.20 & 66.67 & 10.13 & 17.72 & 34.18 \\
Datura metel & 11.10 & 24.36 & 48.72 & 6.89 & 13.17 & 16.96 \\
Ocimum sanctum & 19.48 & 44.67 & 49.35 & 23.68 & 34.21 & 39.47 \\
Zingiber officinale & & & & & & \\
\hline
\end{tabular}

$*=$ Test fungi.

The inhibitory effect of the plant extracts might be attributed to the presence of antifungal compounds. Antifungal activity of different plant extracts have been reported earlier by several investigators against a number of plant pathogens ${ }^{(11,13,14,25)}$.

The data with regard to fungicidal effect on the radial growth of Fusarium solani and F. oxysporum are presented in Table 5. All the fungicides inhibited the radial growth of the test fungi. The extent of growth inhibition, however, varied amongst the five fungicides. The results of the evaluation of fungicides on radial growth of F. solani and $F$. oxysporum showed that all the selected fungicides strongly inhibited the growth of the test fungi at $500 \mathrm{ppm}$ concentrations. 
The highest inhibition of growth of $F$. solani was observed with vitavax 200B (97.87\%), which was followed by agridazim 50 wp (97.23\%), cozeb 80 wp (96.81\%), sunvit $50 \mathrm{wp}(96.81 \%)$ and newban $72 \mathrm{wp}(94.89 \%)$. In case of F. oxysporum, vitavax caused the maximum inhibition (98.73\%). Agridazim $50 \mathrm{wp}$, cozeb $80 \mathrm{WP}$, newban $72 \mathrm{wp}$ and sunvit $50 \mathrm{wp}$ were responsible for $98.61,95.95,96.46$ and $91.14 \%$ inhibition of $F$. oxysporum, respectively at 500 ppm concentration.

Table 5. Fungitoxicity of fungicides on the radial growth of the test fungi at $500 \mathrm{ppm}$ concentration.

\begin{tabular}{lcc}
\hline \multirow{2}{*}{ Name of fungicides } & \multicolumn{2}{c}{ \% inhibition of radial growth } \\
\cline { 2 - 3 } & Fusarium solani $^{*}$ & F. oxysporum \\
\hline Agridazim $50 \mathrm{wp}$ & 97.23 & 98.61 \\
Cozeb $80 \mathrm{wp}$ & 96.81 & 95.95 \\
Newban $72 \mathrm{wp}$ & 94.89 & 96.46 \\
Sunvit 50 wp & 96.81 & 91.14 \\
Vitavax 200 B & 97.87 & 98.73 \\
\hline
\end{tabular}

$*$ Test fungi.

Laboratory evaluation of fungicides revealed that all the fungicides caused maximum inhibition of Fusarium solani and F. oxysporum at 500 ppm concentration (Table 5). Similar observations have also been reported for other fungicides by Vishwakarma and Basu Chaudhury(26) and Bashar ${ }^{(3)}$. In vitro efficacy of various fungicides against the test fungi indicates that vitavax $200 \mathrm{~B}$ and agridazim $50 \mathrm{wp}$ showed promising results as compared to others. Present study revealed that Trichoderma spp., Datura metel, Cassia alata and Vitavax can effectively control the growth of Fusarium spp. the natural enemies of brinjal plant.

\section{References}

1. BAKB 2011. Bangladesh Agricultural Knowledge Bank and Learning Centre. http://bakbbd.org/brinjal production. php.

2. Chakraborty MR, NC Chatterjee and TH Quimio 2009. Integrated management of fusarial wilt of eggplant (Solanum melongena) with soil solarization. Micologia Applicada International 21(1): 25-36.

3. Bashar MA 1992. Laboratory evaluation of some pesticides on Fusarium oxysporum f. sp. ciceri causing wilt of chickpea. Bangladesh J. Bot. 21(1): 157-159.

4. Sanders GM and L Korsten 1999. Survey of fungicide resistance of Colletotrichum gloeosporioides from different avocado production areas. South African Avocado Growers' Association Yearbook 22: 35-38.

5. Ker-Chung Kuo 2001. Sensitivity of mango anthracnose pathogen, Colletotrichum gloeosporioides, to the fungicide prochloraz in Taiwan. Proc. Natl. Sci. Counc. ROC(B) 25(3): 174-179. 
6. Bashar MA and B Rai 1994. Antagonistic potential of root-region microflora of chickpea against Fusarium oxysporum f. sp. ciceri. Bangladesh J. Bot. 23(1): 13-19.

7. Howell CR 2003. Mechanisms employed by Trichoderma species in the biological control of plant diseases : The history and evolution of current concepts. Plant Dis. 87: 4-10.

8. Wool SL and M Larito 2007. Exploiting the interactions between fungal antagonists, pathogens and the plant for biocontrol. In : Novel biotechnologies for biocontrol agent enhancement and management.(Vurro M and J Gressel Eds). Springer Press, Amsterdam, Netherland. pp. 107-130.

9. Versa M, K Satinder, RD Tyagi, RY Surampalli and JR Valéro 2007. Antagonistic fungi, Trichoderma spp.: Panoply of biological control. Biochemical Engineering Journal. 37(1): $1-20$.

10. Shafiquzzaman S, UK Yusuf, K Hossain and S Jahan 2009. In vitro studies on the potential Trichoderma harzianum for antagonistic properties against Ganoderma boninense. J. Food Agri. and Environ. 7(3\&4): 970-976.

11. Siva N, S Ganesan, N Banumathy and Muthuchelian 2008. Antifungal effect of extract of some medicinal plants against Fusarium oxysporum causing wilt disease of Solanum melongena L. Ethnobotanical Leaflets 12: 156-163.

12. Najar AG, A Anwar, L Masoodi and MS Khar 2011. Evaluation of native biocontrol agents against Fusarium solani f. sp. melongenae causing wilt disease of brinjal in Kashmir. Journal of Phytology 3(6): 31-34.

13. Kuri SK, MR Islam and U Mondal 2011. Antifungal potentiality of some botanical extracts against important seed borne pathogen associated with brinjal seeds, Solanum melongena L. J. Agric. Technol. 7(4): 1134-1153.

14. Ankita S and SK Dwivedi 2012. Bioefficacy of plant extracts against Fusarium species causing wilt in pulses. 2: 136-144.

15. Skidmore $\mathrm{AM}$ and $\mathrm{CH}$ Dickinson 1976. Colony interaction and hyphal interference between Septoria nodorum and phylloplane fungi. Trans. Br. Mycol. Soc. 66: 57-64.

16. Fokkema NJ 1976. Antagonism between fungal saprophytes and pathogens on aerial plant surfaces. In: Microbiology of Aerial Plant Surfaces (Dickinson CH and TF Preece Eds), Academic Press, London. pp. 487-505.

17. Pennycook SR and JB Corbin 1970. A preliminary laboratory assessment of fungicides for the control of Sclerotinia scleretiorum (LIB) DBY. Tone 16: 21-30.

18. Upadhyay RS and B Rai 1987. Studies on antagonism between Fusarium udum Butler and root-region microflora of pigeon pea. Plant and Soil 101: 79-93.

19. Chakraborty MR, S Dutta, S Ojha and NC Chatterjee 2004. Antagonistic potential of biocontrol agents against Botryodiplodia theobromae causing die-back of bottle brush (Callistemon citrinus). Acta Botanica Hungarica 46: 279-286

20. Li JY and GA Strobel 2001. Jesterone and hydroxy-jesterone antioomycete cyclohexenone epoxides from the endophytic fungus Pestalotiopsis jesteri. Phytochemistry 57: 261-265.

21. Li JY, J Harper, DM Grant, BO Tombe, B Bashyal, WM Hess and GA Strobel 2001. Ambuic acid, a highly functionalized cyclohexenone with antifungal activity from Pestalotiopsis spp. and Monochaetia sp. Phytochemistry 56: 463-468. 
22. Kexiang G, L Xiaoguang, L Youghong, Z Tianbo and W Shuliang. 2002. Potential of Trichoderma harzianum and T. atroviride to control Botryosphaeria berengeriana f. sp. piricola, the cause of apple ring rot. Phytopathol. 150: 271-276.

23. Krupke AO, AJ Castle and DL Rinker. 2003. The North American mushroom competitor, Trichoderma aggressivum f. aggressivum, produces antifungal compounds in mushroom compost that inhibit mycelial growth of the commercial mushroom Agaricus bisporus. Mycol. Res. 107: 1467-1475.

24. Barakat FM, NM Abada Abou-Zeid and YHE El-Gammal 2013. Effect of volatile and nonvolatile compounds of Trichoderma spp. on Botrytis fabae the causative agent of faba bean chocolate spot. WebPub J. Agric. Res. 1(3): 42-50.

25. Babu J, AD Muzafar and V Kumar 2008. Bioefficacy of plant extracts to control Fusarium solani f. sp. melongenae incitant of brinjal wilt. Global J. Biotechnol. Biochem. 3(2): 56-59.

26. Vishwakarma SN and KC Basu Chaudhury 1982. Laboratory evaluation of some fungicides against some root rot disease pathogens of gram. Phytopath. 35: 624-627.

(Manuscript received on 4 November, 2013; revised on 17 December, 2013) 